\title{
CONSIDERAÇÕES A RISCOS GEOTÉCNICOS EM BARRAGENS DE REJEITO
}

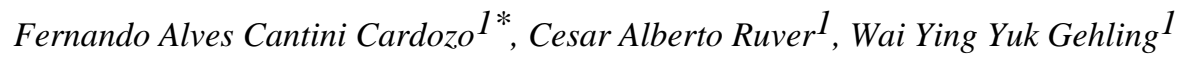 \\ ${ }^{1}$ Departamento de Engenharia Civil, UFRGS/DECIV, 9085000, Porto Alegre, Brasil.
}

*E-mail: fernando.cantini3@hotmail.com

\section{RESUMO}

Este trabalho visa abordar os riscos associados a barragens de rejeito da mineração quanto à influência de variações de parâmetros de projeto frente a estabilidade da estrutura e possíveis alternativas de projeto que visem a minimização de Riscos. Para tanto foi realizada por meio da estruturação de modelos computacionais de barragens hipotéticas, com parâmetros de projeto baseados em dados reais de caracterização de materiais disponíveis em bibliografia, a verificação do comportamento das estruturas frente a variações de parâmetros geotécnicos e de projeto, onde se verificou a sensibilidade do método construtivo frente a tais variações. Verificou-se que o método de alteamento a montante possui sensibilidade a variações, principalmente a critérios relacionados com a drenagem (interna e externa). Avaliou-se também o uso de análise probabilística como ferramenta para melhor entendimento dos riscos associados a um barramento e quais os parâmetros de entrada tem maior relevância. Viu-se que tal ferramenta possui grande potencial de aplicação. Quanto a minimização de riscos são apresentadas metodologias e premissas de projetos e de monitoramento que visam a gerência sobre os riscos associados a estrutura.

Palavras-chave: Engenharia Geotécnica. Barragens de Rejeito. Mineração. Análise de Risco.

\section{Introdução}

Barragens de Rejeito estão entre as maiores estruturas construídas pelo homem, juntamente com as pilhas de estéril [1]. Estas estruturas tem a função de acondicionar, de maneira estável e segura, todo o rejeito proveniente dos processos de beneficiamento mineral, especificamente, das etapas de concentração, sendo estas normalmente posteriores a etapas de moagem. Tipicamente as operações de moagem de minérios apresentam redução granulométrica do minério para faixas inferiores a $15 \mu \mathrm{m}$ [2]. De modo geral, posteriormente a execução das operações unitárias de concentração gravíticas, hidrometalurgicas e/ou físico químicas, seguintes as etapas de cominuição, a disposição em barragem é o destino final mais comum dos rejeitos destes processos. Quanto aos materiais barrados, pode se dizer que são principalmente rejeitos dos processos de hidrometalurgia e físico-químicos, nos quais, cabe salientar, adquirem características reológicas.

Segundo Curi [1], a atividade de mineração é uma das mais antigas realizadas pela humanidade e tem papel fundamental na qualidade de vida da mesma, sendo assim imprescindível para a sociedade. Assim, tal atividade merece atenção quanto a sua execução e suas estruturas, onde em caso de falha apresentam grande potencial de ocorrência de danos sociais, ambientais e financeiros; caso das barragens de rejeito. Rupturas em barragens podem acarretar tipicamente na liberação de milhões de metros cúbicos de rejeito, os quais são de potencial risco a saúde humana e a integridade de ecossistemas, como elenca Venâncio Aires et al. [3] e Burritt et al. [4]. Dada sua natureza e fatores construtivos, barragens de rejeito são estruturas que apresentam maior propensão a falhas se comparadas com barragens para reservação de água [5-7]. Enquanto barragens ditas civis tem a função geral de reservação de água e são executadas integralmente, as barragens para contenção de rejeitos são executadas concomitantemente à operação de lavra da mina, que gera os rejeitos. Assim tem-se uma peculiaridade, onde fatores como planejamento de lavra, pesquisa mineral e beneficiamento entram como critérios a serem levados em consideração no projeto e na execução de uma barragem de rejeito, uma vez que são responsáveis por parâmetros como taxa de disposição do rejeito, mineralogia e granulometria dos mesmos.

Assim como toda uma operação de mineração, a qual pode apresentar custo na ordem de milhões de dólares, a depender das dimensões e tipo de depósito mineral [1], as barragens de contenção de rejeito, por serem estruturas diretamente proporcionais a escala produtiva e vida útil da mina, podem ser estruturas que venham a apresentar altos custos de projeto e execução. Segundo Xin et al.[8], entre 5 e $10 \%$ de todo o custo com a operação mineira (pesquisa mineral, preparação do terreno, aquisição de equipamentos, estruturas auxiliares, entre outras), é desprendido com o projeto, execução e gestão das barragens de rejeito. Outro fator que lança luz sobre a necessidade de adequados 


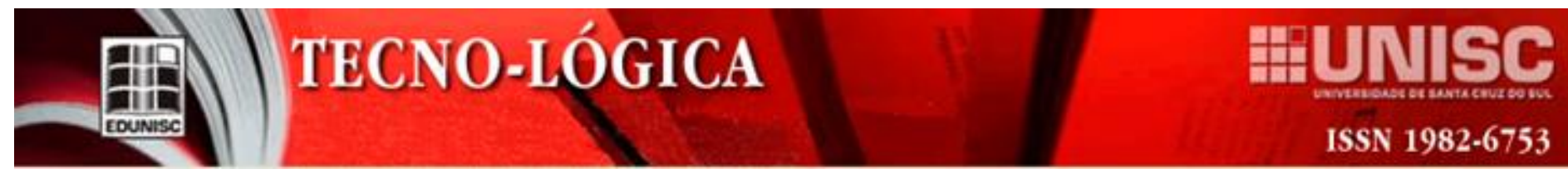

estudos e projetos de barramentos é sua temporalidade, pois mesmo após o termino da exploração mineral, a barragem de rejeito (salvo em situações de medidas alternativas) é uma estrutura com risco permanente de ruptura e de todos os danos oriundos da possível falha. Destaca-se neste ponto, que embora trata-se de estrutura artificial, assim como para estruturas geotécnicas naturais (encostas), a passagem do tempo se torna contraproducente à estabilidade da estrutura, uma vez que não executada a manutenção e monitoramento corretos, podemos ter situação análoga a encostas onde a passagem do tempo é agente desestabilizante [9].

Deste modo fica implícita a importância do estudo acerca destas estruturas, bem como dos riscos que incorretas considerações nos projetos podem ter frente à estabilidade das mesmas. Assim, este trabalho se propõem a avaliar conceitos acerca de situações de riscos geotécnicos referentes a barragens de rejeito e como certos parâmetros considerados em projetos, influenciam na estabilidade de um barramento. Neste mesmo sentido são apresentadas medidas que visam a atenuação de riscos na disposição de rejeitos de mineração.

\subsection{Métodos construtivos de barragens de rejeito}

Os métodos construtivos usualmente empregado fazem referência a técnica de alteamento, sendo estes denominados em função da posição e direção de execução do alteamento, o qual pode ser executado com material proveniente de áreas de empréstimo ou com o próprio rejeito do beneficiamento, desde que tratado e que atenda especificações geotécnicas de projeto. Para tanto, este rejeito é passível de processos adicionais, como a ciclonagem, para deslamagem, passando a ser chamado de aterro hidráulico [10]. De Araújo [11] comenta que no uso de hidrociclones, em seu estudo de caso, o underflow (saída com material mais grosseiro) apresenta $78 \%$ de sólidos em peso e o overflow apresenta por sua vez $35 \%$. Por ser a porção com menor umidade e tipicamente ser mais granular, o produto do underflow é destinado para uso como material construtivo dos alteamentos.

Na Figura 1, são apresentados os métodos construtivos empregados tipicamente em barragens de rejeito.

Nota-se (conforme Figura 1) que diferente do método de alteamento a Jusante, nos métodos de alteamento da Linha de Centro e de Montante, os alteamentos são executados parcialmente sobre o rejeito já disposto. Tal fator, embora gere significativa economia com movimentação de terra (apresentam menor volume de material destinado a execução do barramento), traz certa complexidade quanto ao controle construtivo do barramento e quanto a execução e controle de drenagem [12].

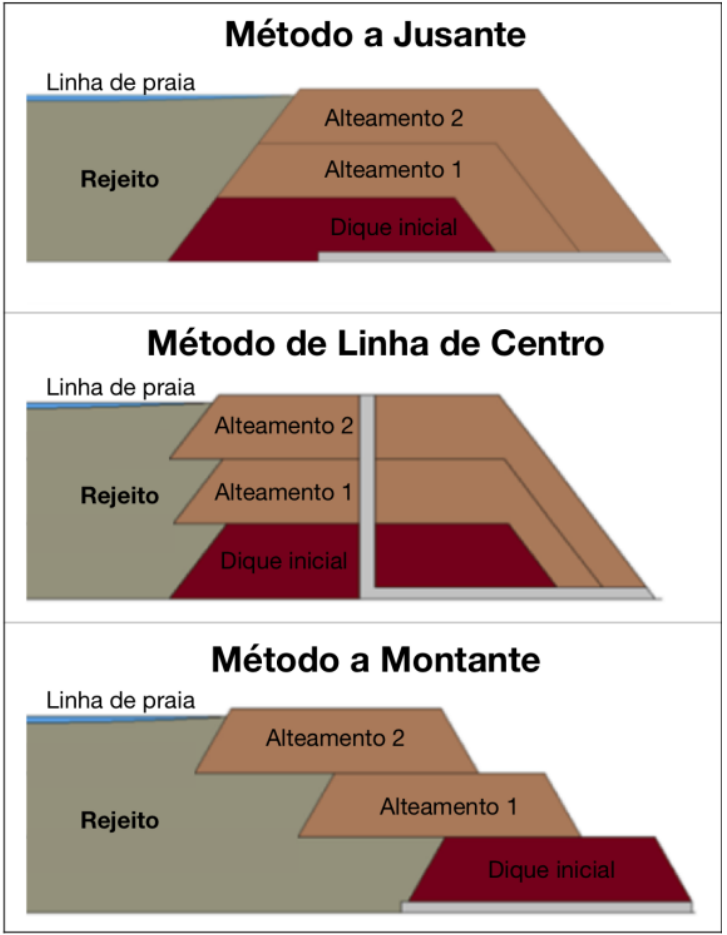

Figura 1 - Métodos construtivos de barragens de rejeito.

Embora a comparação entre os métodos construtivos de barragens de rejeito seja tema complexo, devido a critérios conceituais de projeto, como o sistema de drenagem, trabalhos como os de De Araújo [11]; Rout, Sahoo e Das [13]; Cardozo et al. [14]; e Santos et al. [15], apresentam tais comparações, concluindo pela maior complexidade e suscetibilidade à falha para o método de montante, de acordo com os parâmetros de projeto envolvidos. Sobretudo, destacam-se neste método as dificuldades com drenagem, controle tecnológico de matérias e do adensamento sob alteamentos (diferentes níveis de compactação do rejeito).

\subsection{Riscos associados as fases de implementação e operação de Barragens de Rejeito}

Leite e Gundim [16] comentam que desde que as atividades industriais se tornaram uma realidade da sociedade moderna, o conceito de risco foi naturalmente incorporado como algo inerente ao próprio trabalho, surgindo a necessidade de realizar o seu controle e gestão, com o intuito de reduzir a probabilidade de ocorrência e suas consequências a níveis, no mínimo, aceitáveis. Quanto a aplicação específica da gestão de riscos na mineração e barragens de rejeito, pode-se entender que como as demais aplicações, os riscos devem ser geridos nas diferentes fases de projeto (Figura 2) [8,16-17].

Tal gerenciamento inclui, primeiramente, a caracterização dos riscos e compreensão dos fenômenos 


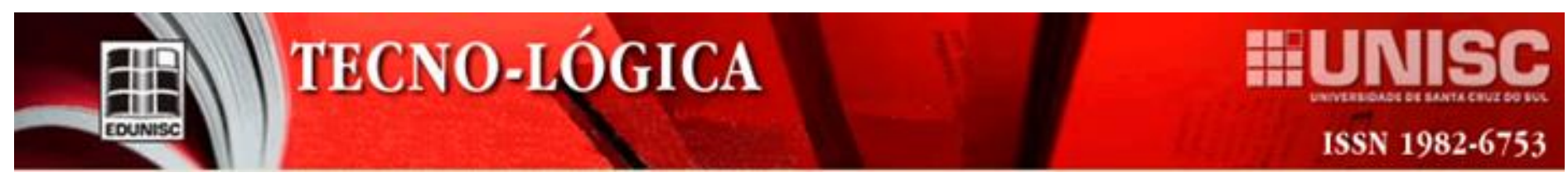

associados e como afetarão a infraestrutura e o empreendimento. Assim, pode se dizer que uma análise de sensibilidade, onde se verifica a sensibilidade de um modelo a variações de parâmetros de projeto (ou de um modelo tomado como base), é parte constituinte de uma Análise de Risco. As situações de risco podem ser geradas nas fases de projeto, execução, operação e gestão.

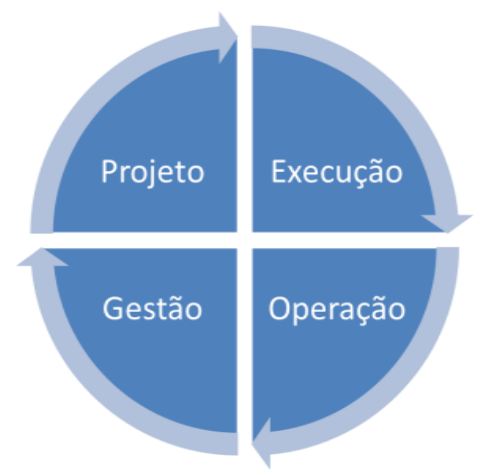

Figura 2 - Fases de potencial risco relacionadas às barragens de rejeito.

Pode-se especificar, dentro das fases e etapas de projeto, implementação e operação de uma barragem de rejeito, subitens que podem vir a contribuir para a ocorrência de falhas, sendo potenciais geradores de risco:

*Projeto:

- Incorretas investigações de campo e de fundação

-Caracterização inadequada do rejeito

-Falta de expertise no tema

*Execução:

-Utilização de materiais inadequados

-Falha no controle de qualidade

-Propagação de falhas do projeto

*Operação:

-Falta de expertise ao tema

-Drenagem inadequada

-Monitoramento insuficiente ou inadequado

*Gestão:

-Falta de transparência na gestão

-Tomadas de decisão inadequadas

-Inadequada avaliação de riscos
Entendesse que para o caso de estruturas geotécnicas, onde se enquadram as barragens de rejeito, diversos destes aspectos de risco irão convergir para variações negativas na confiabilidade da estrutura, representando decréscimo no Fator de Segurança (F.S.) e aumento da probabilidade de falha da estrutura. Por sua vez, considerando a possível propagação de erros e dificuldades associadas a mitigação, a fase de projetos mostra-se como uma das mais problemáticas para o caso de barragens, normalmente devido a problemas de caracterização.

\section{Análises de Riscos associados a Barragens de Rejeito}

\subsection{Metodologia}

Para o presente trabalho se escolheu analisar a variação de estabilidade para barragens alteadas pelo método de montante, em função das hipóteses que deveriam ser avaliadas e atenuadas em análises de riscos, estas em termos da estabilidade da estrutura. Para tanto, com intuito a dar uniformidade ao estudo, se escolheu trabalhar com geometria e parâmetros geotécnicos de projeto, baseados em trabalhos disponíveis em bibliografia, como os de Araújo [11], Rafael e Romanel [18], Rout et al.[13], Palmeira et al. [19], entre outros. A Tabela 1 apresenta uma compilação dos estudos e seus parâmetros considerados como indicativos de propriedades geométricas, geotécnicas e hidráulicas dos materiais, a serem utilizadas em projetos de barramento de rejeitos de mineração.

Salienta-se que nenhum dos estudos elencados na Tabela 1 é explicitamente explicativo quanto aos sistemas de filtro e/ou drenagem empregados e seus dimensionamentos.

Observa-se também, que materiais (rejeitos) de minerações de mesmo minério, apresentam certa variabilidade de parâmetros geotécnicos, fato que vai ao encontro dos diferentes processos de beneficiamento, os quais são responsáveis por conferir aos materiais características geotécnicas e hidráulicas diversas, como demonstra o trabalho de Da Silva et al. [20].

Para determinação de parâmetros hidráulicos dos materiais a constituírem a estrutura (alteamentos e rejeitos), uma opção frente a ensaios de laboratório ou ensaios de campo, é a utilização de modelos matemáticos para determinação dos parâmetros (kh, kv e/ou razão kh/kv), como apresentam Shamsai et al. [23], Albuquerque Filho [21], entre outros. 
Tabela 1 - Propriedades geotécnicas e geométricas para rejeitos de mineração e barramentos

\begin{tabular}{|c|c|c|c|}
\hline Estudo & Material & Alteamento & Propriedades \\
\hline $\begin{array}{l}\text { Da Silva } \\
\text { et al. }[20]\end{array}$ & $\begin{array}{l}\text { Minério de } \\
\text { Ferro }\end{array}$ & - & $\begin{array}{l}\text { Rejeito: } \\
\mathrm{K}_{\mathrm{h}}: 1,62 * 10^{-3} \mathrm{~m} / \mathrm{s} \\
\text { a } 4,44 * 10^{-7} \mathrm{~m} / \mathrm{s}\end{array}$ \\
\hline $\begin{array}{l}\text { Albuquer } \\
\text { que Filho } \\
\text { [21] }\end{array}$ & $\begin{array}{l}\text { Minério de } \\
\text { Ferro }\end{array}$ & $\begin{array}{l}\text { Montante } \\
\mathrm{i}_{\mathrm{m} \text { e j: }} 20^{\circ} \\
\mathrm{h}: 10 \mathrm{~m} \\
\mathrm{~b}: 3 \mathrm{~m} \\
\text { \#aterro hidráulico }\end{array}$ & $\begin{array}{l}\text { Rejeito: } \\
\phi^{\prime}: 30-36^{\circ} \text { (granular) e 26- } \\
28^{\circ} \text { (siltoso) } \\
\text { c': nula } \\
\mathrm{K}_{\mathrm{h}}: 1,15^{*} 10^{-5} \mathrm{~m} / \mathrm{s} \\
\text { a } 9,20^{*} 10^{-7} \mathrm{~m} / \mathrm{s}\end{array}$ \\
\hline $\begin{array}{l}\text { Naeini e } \\
\text { Akhtarpo } \\
\text { ur [22] }\end{array}$ & $\begin{array}{l}\text { Minério de } \\
\text { Cobre }\end{array}$ & $\begin{array}{l}\text { Linha de Centro } \\
\mathrm{i}_{\mathrm{j}}: 14^{\circ} \mathrm{i}_{\mathrm{m}}: 27 \quad \mathrm{i}_{\mathrm{p}}: \\
0,5 \% \\
\mathrm{~h}: 10 \mathrm{~m} \\
\mathrm{~b}:- \\
\text { \#aterro hidráulico }\end{array}$ & $\begin{array}{l}\text { Rejeito: } \\
\phi^{\prime}: 35^{\circ} \gamma: 19,2 \text { c': nula } \\
\mathrm{K}_{\mathrm{v}}: 1,4^{*} 10^{-7} \mathrm{~m} / \mathrm{s} \quad-8,7 * 10^{-9} \\
\left.\mathrm{~m} / \mathrm{s} \mathrm{k}_{\mathrm{h}} / \mathrm{k}_{\mathrm{v}}: 10\right) \\
\mathrm{E}: 7000(\mathrm{kPa}) \\
\text { Rejeito ciclonado: } \\
\phi^{\prime} \approx 42^{\circ} \gamma: 19,4 \mathrm{c}^{\prime}: \text { nula } \\
\mathrm{K}_{\mathrm{v}}: 14,9^{*} 10^{-6} \\
\left(\mathrm{k}_{\mathrm{h}} / \mathrm{k}_{\mathrm{v}}: 1 / 0,8\right) \\
\mathrm{E}: 628(\mathrm{kPa}) \\
\text { Fundação: } \\
\phi^{\prime}: 25^{\circ} \gamma: 20,7 \mathrm{c} \text { ': } 10(\mathrm{kPa}) \\
\mathrm{Kv}: 6,0^{*} 10^{-6} \mathrm{~m} / \mathrm{s}(\mathrm{kh} / \mathrm{kv}: 1)\end{array}$ \\
\hline $\begin{array}{l}\text { Rafael e } \\
\text { Romanel } \\
{[18]}\end{array}$ & $\begin{array}{l}\text { Minério de } \\
\text { Cobre }\end{array}$ & $\begin{array}{l}\text { Montante } \\
\mathrm{i}_{\mathrm{m} \text { e j: }} 34^{\circ} \\
\mathrm{h}: 10 \mathrm{~m} \\
\mathrm{~b}: 10 \mathrm{~m} \\
\text { \#aterro hidráulico }\end{array}$ & $\begin{array}{l}\text { Rejeito: } \\
\phi^{\prime}: 32^{\circ} \gamma: 24,0 \text { c': nula } \\
\mathrm{K}_{\mathrm{v}}: 3,0^{*} 10^{-5} \mathrm{~m} / \mathrm{s}\left(\mathrm{k}_{\mathrm{h}} / \mathrm{k}_{\mathrm{v}}: 10\right) \\
\mathrm{E}: 400(\mathrm{kPa}) \\
\text { Rejeito compactado: } \\
\phi^{\prime}: 36^{\circ} \gamma: 24,0 \mathrm{c}^{\prime}: \text { nula } \\
\mathrm{K}_{\mathrm{v}}: 3,47^{*} 10^{-7} \\
\left(\mathrm{k}_{\mathrm{h}} / \mathrm{k}_{\mathrm{v}}: 1 / 0,8\right) \\
\mathrm{E}: 1300(\mathrm{kPa}) \\
\text { Fundação: } \\
\phi^{\prime}: 33^{\circ} \gamma: 18,5 \mathrm{c} \text { ': } 20(\mathrm{kPa}) \\
\mathrm{Kv}: 9,03^{*} 10^{-6} \mathrm{~m} / \mathrm{s}(\mathrm{kh} / \mathrm{kv}: 1)\end{array}$ \\
\hline $\begin{array}{l}\text { De } \\
\text { Araújo } \\
{[11]}\end{array}$ & $\begin{array}{l}\text { Minério de } \\
\text { Ferro }\end{array}$ & $\begin{array}{l}\text { Linha de Centro } \\
\mathrm{i}_{\mathrm{m} \text { e }}: 18,5^{\circ} \\
\mathrm{h}: 5 \mathrm{~m} \\
\mathrm{~b}: 10 \mathrm{~m} \\
\text { \#aterro hidráulico }\end{array}$ & $\begin{array}{l}\text { Rejeito: } \\
\phi^{\prime}: 25^{\circ} \gamma: 20,0 \mathrm{c}^{\prime}: 10 \\
\mathrm{~K}_{\mathrm{v}}: 10^{-6} \mathrm{~m} / \mathrm{s}\left(\mathrm{k}_{\mathrm{h}} / \mathrm{k}_{\mathrm{v}}: 4\right) \\
\text { E: } 200(\mathrm{kPa}) \\
\text { Rejeito compactado: } \\
\phi^{\prime}: 24^{\circ} \gamma: 36,0 \mathrm{c}^{\prime}: \text { nula } \\
\mathrm{K}_{\mathrm{v}}: 10^{-6} \mathrm{~m} / \mathrm{s}\left(\mathrm{k}_{\mathrm{h}} / \mathrm{k}_{\mathrm{v}}: 10\right) \\
\mathrm{E}: 1300(\mathrm{kPa}) \\
\text { Fundação: } \\
\phi^{\prime}: 30^{\circ} \gamma: 20,0 \mathrm{c}: 20(\mathrm{kPa}) \\
\text { Kv: } 10^{-6} \mathrm{~m} / \mathrm{s}(\mathrm{kh} / \mathrm{kv}: 1)\end{array}$ \\
\hline $\begin{array}{l}\text { Rout, } \\
\text { Sahoo e } \\
\text { Das [13] }\end{array}$ & $\begin{array}{l}\text { Minério de } \\
\text { Alumínio }\end{array}$ & $\begin{array}{l}\text { Montante } \\
\text { Jusante } \\
\text { Linha de Centro } \\
\mathrm{i}_{\mathrm{m} \mathrm{e} \mathrm{j}} \approx 27^{\circ}\end{array}$ & $\begin{array}{l}\text { Rejeito: } \\
\phi^{\prime}: 25^{\circ} \gamma: 18,37 \mathrm{c}^{\prime}: 25,3 \\
\mathrm{~K}_{\mathrm{v}}: 4,6^{*} 10^{-9} \mathrm{~m} / \mathrm{s}\left(\mathrm{k}_{\mathrm{h}} / \mathrm{k}_{\mathrm{v}}: 1\right) \\
\text { E: } 1500(\mathrm{kPa}) \\
\text { Rejeito compactado: } \\
\phi^{\prime}: 34^{\circ} \gamma: 21,0 \mathrm{c}^{\prime}: 28,8 \\
\mathrm{~K}_{\mathrm{v}}: 4,6^{*} 10^{-9} \mathrm{~m} / \mathrm{s}\left(\mathrm{k}_{\mathrm{h}} / \mathrm{k}_{\mathrm{v}}: 1\right) \\
\mathrm{E}: 1771(\mathrm{kPa}) \\
\text { Barramento inicial: } \\
\phi^{\prime}: 8^{\circ} \gamma: 16,0 \mathrm{c}^{\prime}: 158,7(\mathrm{kPa}) \\
\mathrm{Kv}: 10^{-10} \mathrm{~m} / \mathrm{s}(\mathrm{kh} / \mathrm{kv}: 1)\end{array}$ \\
\hline
\end{tabular}

Onde: $\phi$ ': ângulo de atrito efetivo; c': coesão; $\mathrm{K}_{\mathrm{h}}$ : condutividade hidráulica horizontal; $\mathrm{K}_{\mathrm{v}}$ : condutividade hidráulica vertical; $\mathrm{E}$ : modulo de Young; $\mathrm{i}_{\mathrm{j}}$ : inclinação do barramento a jusante; $\mathrm{i}_{\mathrm{m}}$ : inclinação do barramento a montante; $\mathrm{i}_{\mathrm{p}}$ : inclinação da praia de rejeito; h: altura do por alteamento; b: largura de berma.

\subsubsection{Modelos}

Os modelos estudados foram inicialmente criados em CAD (computer aided design), no software AutoCad, e posteriormente importados no software Slide, da empresa Rocscience. A linha piezométrica, os gradientes hidráulicos e a distribuição de poropressões foram determinados no mesmo software, por método numérico, e posteriormente utilizadas na análise analítica onde estes são influentes na determinação dos Fatores de Segurança (F.S.). Para todas as análises, foi utilizado o critério de ruptura de Mohr-Coulomb. Para o cálculo de todos os fatores de segurança foi utilizado o Método de Bishop Simplificado, utilizando-se uma discretização por 50 lamelas. Referente a determinação dos parâmetros associados ao fluxo d'água, estes foram determinados considerando uma discretização por 4000 nós e elementos triangulares para todas as análises, sendo estes parâmetros determinados pelo software via Método dos Elementos Finitos (MEF).

Com base nos dados disponíveis em bibliografia (Tabela 1), se optou por considerar modelos de barragens sintéticas constituídas por cinco materiais (fundação, argila mole, aterro, rejeito disposto e rejeito adensado), com propriedades segundo a Figura 3, de modo que os parâmetros considerados não fugissem da realidade apresentada por materiais reais, embora por simplificação optou-se por considerar os materiais isotrópicos. Conforme o levantamento feito em bibliografia, os parâmetros considerados para rejeitos e aterro (considerado este constituído por aterro hidráulico, logo por rejeito ciclonado), são compatíveis com propriedades oriundas de minérios metálicos (como ferro ou cobre), vide as altas densidades.

Como método construtivo, devido a sua maior relevância, optou-se pelo método de alteamento a Montante. Utilizou-se um modelo computacional com alteamentos de 10 (dez) metros intercalados por bermas de 10 (dez) metros, sendo os taludes considerados com inclinação de $25^{\circ}$ (Figura 3 ). Considerou-se como Modelo Base um barramento com 6 alteamentos, totalizando um barramento global de 60 metros de altura. Para a configuração da praia de rejeito, foram utilizados os parâmetros de projeto conforme Silva [24] e De Araújo [11], que baseados em modelos empíricos e observacionais, consideraram em seus estudos a existência de duas fases distintas, onde a porção submersa apresenta uma maior inclinação em relação a porção emersa. Tal fenômeno é bem descrito em trabalhos como os de De Araújo [11] 


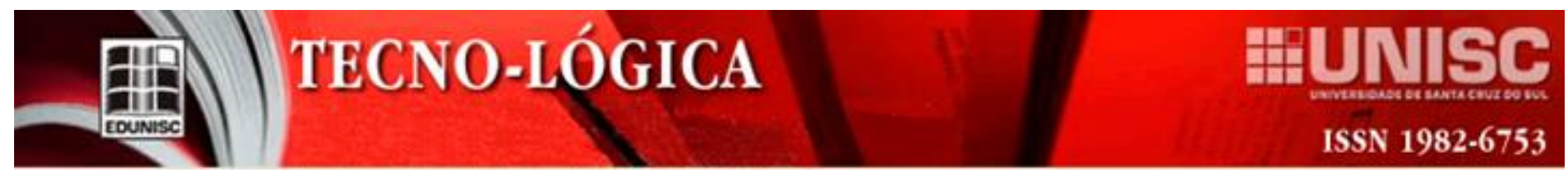

Machado [1], que citam os estudos hoje clássicos de Vick ${ }^{1}$ apud (De Araújo [11]).

Para o Modelo Base foi considerada uma praia de rejeito de 150 metros de extensão entre o ponto de pivotamento teórico do rejeito, no barramento, e a linha d'água sobre a qual o rejeito submerge, tipicamente com maior angulação, como salienta Silva [24]. Quanto as inclinações adotadas, se considerou uma inclinação (i) de $0,5 \%$ para o rejeito emerso e de $3,0 \%$ para o rejeito submerso.
Referente ao sistema de filtro/dreno, foi utilizado no modelo filtros de pé e meio de barramento, de forma a percorrer metade do pé e toda a extensão central do alteamento, assim possibilitando sua continuidade no decorrer dos alteamentos. Adotou-se a espessura de 1 metro, bem como, kh e kh/kv compatível com brita graduada como meio filtrante, ou seja, respectivamente, $10^{-3} \mathrm{~m} / \mathrm{s}$ e 1 , valores estes condizentes com o estudo apresentado por Dias [25]. Como parâmetros geotécnicos para os drenos se considerou de forma simples, c': $0, \gamma: 20 \mathrm{kN} / \mathrm{m}^{3}$ e $\varphi: 37^{\circ}$, uma vez que estes são parâmetros compatíveis com material pétreo cominuído (brita graduada).

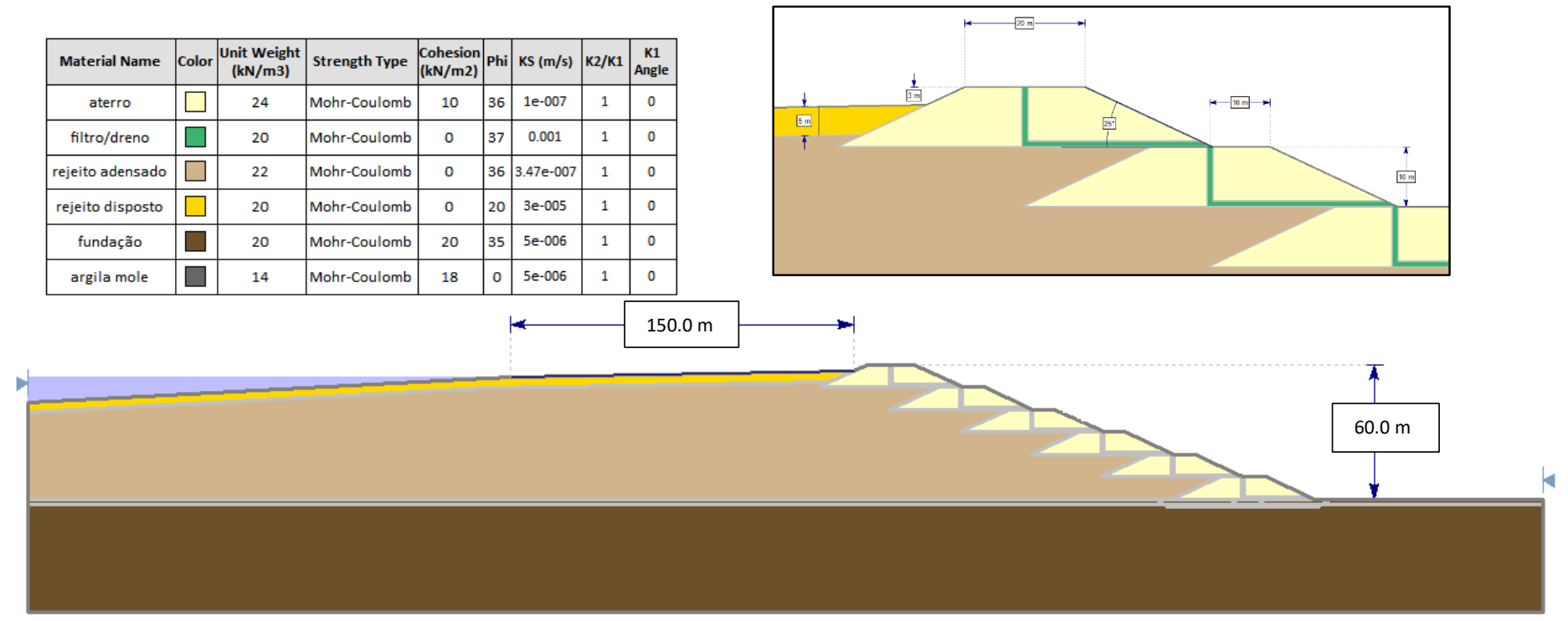

Figura 3 - Layout do modelo base de estudos e materiais de construção

A Figura 4 apresenta o resultado obtido para o modelo base, considerando o efeito da poropressão gerado pelo fluxo d'água. A linha em cor azul representa a linha piezométrica gerada por método numérico (MEF). Observa-se um F.S. de 2.186.

As Figuras 5 e 6 representam, respectivamente, a distribuição de poropressão e o detalhe do gradiente hidráulico, ambas determinadas no software pelo método de elementos finitos. Observa-se que o modelo de filtro/dreno mostra-se eficiente para o problema proposto, embora seja pouco exigido devido ao afastamento da linha freática dos barramentos superiores.

\footnotetext{
${ }^{1}$ VICK, S.G., 1983 - Planning, Design, and Analysis of Tailings Dams, Wiley Interscience, New York
}

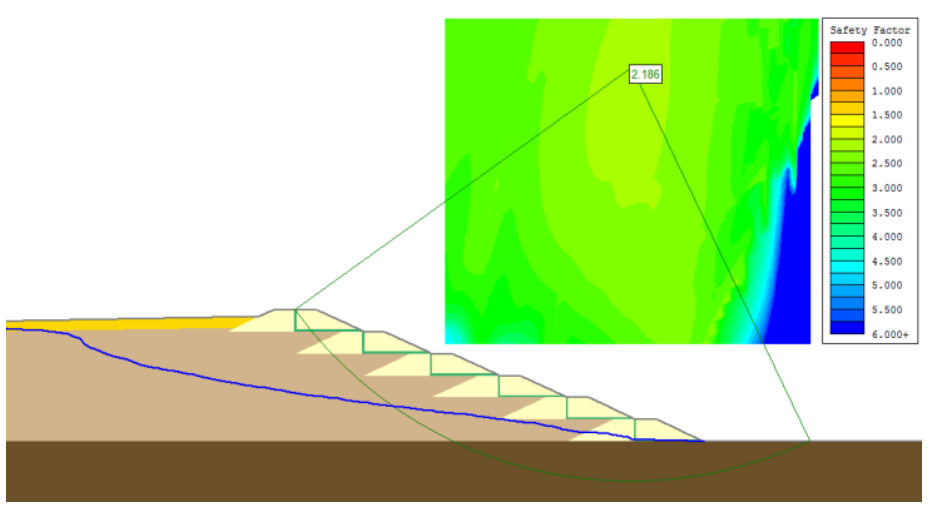

Figura 4 - Análise do F.S. para o Modelo Base e superfície de ruptura, considerando o sistema de drenagem, com F.S. calculado de 2.186. 


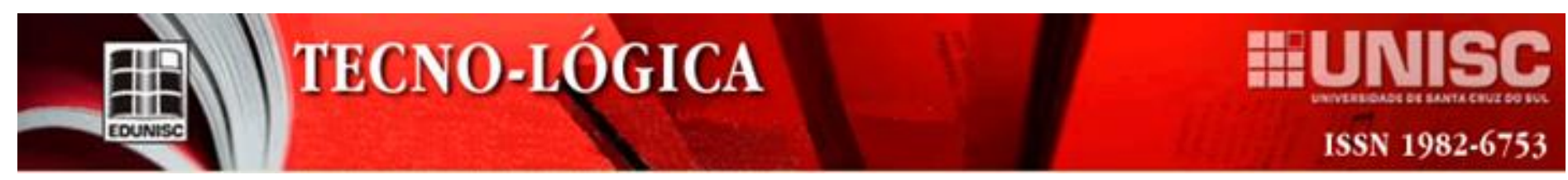

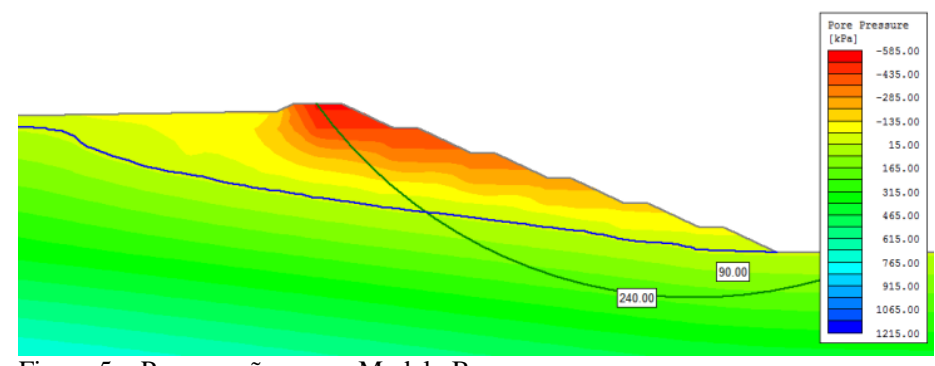

Figura 5 - Poropressão para o Modelo Base.

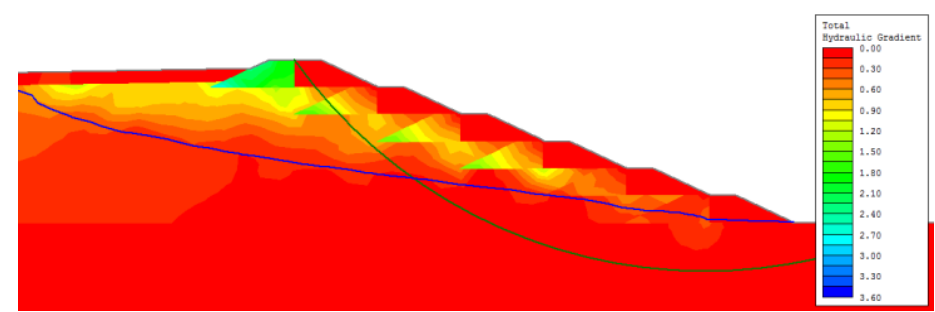

Figura 6 - Gradiente hidráulico para o Modelo Base.

Salienta-se, que todos os demais cenários estudados consideraram os efeitos de poropressão gerados pelo fluxo d'água como forças mobilizantes, ou seja, que contribuem no cálculo da estabilidade.

\subsection{Variações de Parâmetros do Modelo Base}

Para o estudo da influência das variações dos parâmetros no modelo geotécnico, foram executadas mudanças geométricas e de input de parâmetros do modelo, de forma que estas representem alterações decorrentes de situações consideradas de riscos ou geradoras de situações de risco. Considerou-se as hipóteses de variações de propriedades geotécnicas dos materiais, de parâmetros hidráulico e geométricos do barramento hipotético (Modelo Base).

\subsubsection{Fundação}

Diversos autores comentam ser a fundação item de grande atenção, independente da finalidade do barramento, vide seu potencial de falha. São constantes as recomendações para desenvolvimentos de estudos, pesquisas e caracterizações geotécnicas adequadas, no intuito de minimizar o desconhecimento quanto as camadas sobre as quais o barramento será executado $[9,26]$.

Para avaliar o efeito das características do terreno de fundação (base) do barramento, se avaliou a influência de eventual ocorrência de camada de argila mole sob o material de fundação; posteriormente se avaliou a execução de uma substituição de tal camada sob o barramento inicial. Verifica-se que esta porção (fundação) tem grande influência sobre o F.S. do modelo, e principalmente quanto a posição da superfície de ruptura. No modelo hipotético de barragem sob argila mole, a camada considerada de solo de baixa resistência (ângulo de atrito nulo) consistia de uma espessura de 2 metros. Para o caso de tratamento da fundação considerou-se além da substituição da camada (argila mole) a escavação de 1 metro sob tal camada. É possível observar, a seguir, o modelo considerando a camada de argila mole sob o barramento (Figura 7) e consequente substituição total da mesma sob o barramento inicial (Figura 8).

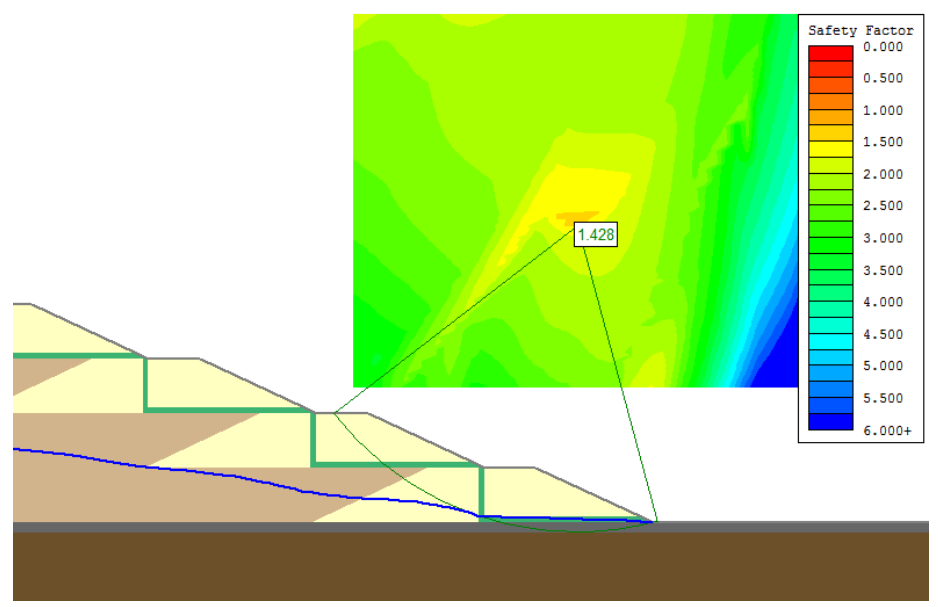

Figura 7 - Ruptura sob a camada de argila mole no barramento inicial, modelo sem tratamento de fundação, F.S. 1,428.

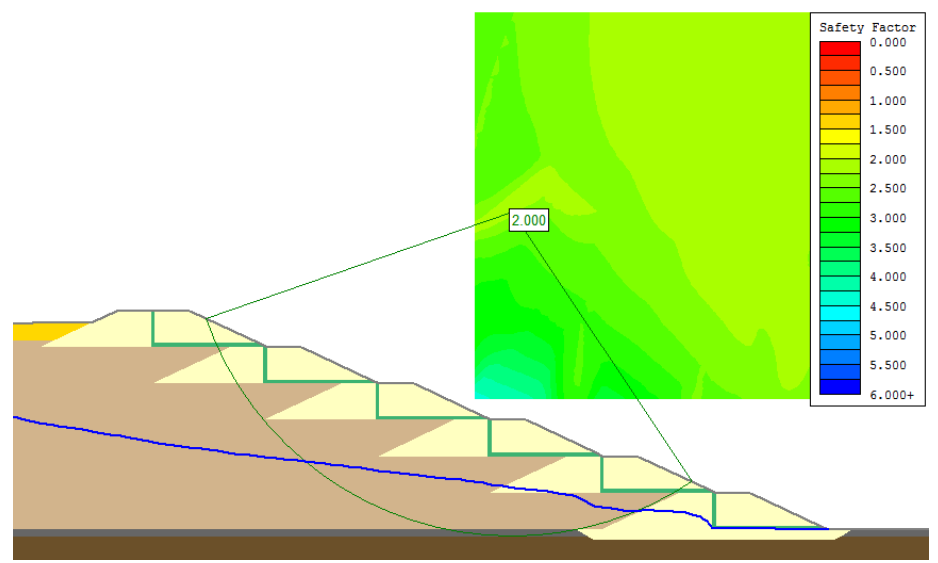

Figura 8 - Modelo com substituição da camada de argila mole, F.S. 2,00.

Observa-se que para tal caso, a existência de um solo com baixa resistência ao cisalhamento, com ângulo de atrito nulo, faz com que a superfície de ruptura crítica passe por este material, causando uma queda abrupta do F.S. para 1,428 (no modelo considerado). Considerando o tratamento da fundação passamos para um F.S. de 2,000. 


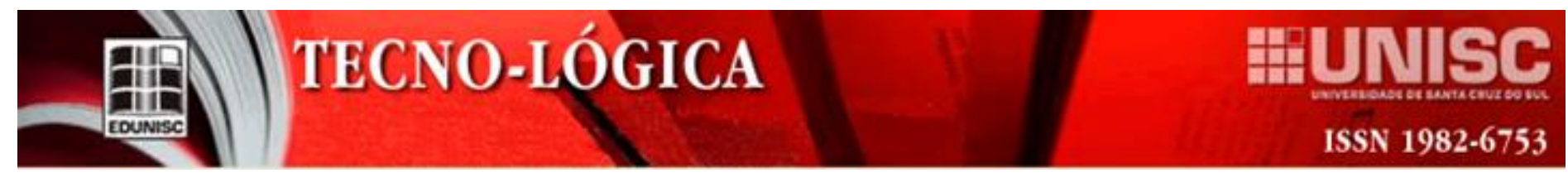

\subsubsection{Variações de posição da linha de praia}

Assim como em barramentos destinados a reservação de água, os parâmetros hidráulicos dos materiais e os níveis d'água, bem como sua variação, devem ser considerados desde os estudos conceituais de projeto. Quanto a barragens de rejeito este aspecto deve levar em consideração que trata-se uma polpa com fase sólida e líquida, em que podem vir a se alterar as razões entre ambas, assim como outros parâmetros de interesse como as inclinações de praia (ângulo de repouso) e a posição da transição entre as fases (linha d'água). Sabidamente uma das melhores medidas para conferir confiabilidade e estabilidade a um barramento de rejeito é afastar a linha d'água do barramento, tal como o Modelo Base, onde tem-se uma distância de $150 \mathrm{~m}$ entre a linha d'água e o barramento. Pode -se observar, vide Figuras 7 e 8 , supra apresentadas, que o tal afastamento afasta da superfície de ruptura da barragem a linha piezométrica diminuindo forças mobilizantes (poropressões positivas).

Como exemplificação, nas Figuras 9, 10 e 11; são apresentadas análises do barramento em estudo com o deslocamento da linha d'água para posições de 75 (Figura 9),0 metros (Figura 10) do barramento e com linha d'água 1,5 metros acima do rejeito (ou seja, também coincidente com o último barramento). Nestes casos o F.S. passa para 2,148, a 75 metros do barramento; 2,130, coincidindo com o barramento (zero metros) e; 2,119, com a elevação de 1.5 metros do nível d'água. Nota-se pela variação dos F.S. que a proximidade da linha d'água com o barramento afeta negativamente o F.S., nota-se como justificativa deste fenômeno a posição linha piezométrica e diferença da distribuição de poropressões.

Demais variações em parâmetros hidráulicos dos materiais geotécnicos (rejeitos dispostos), também afetam a estabilidade do barramento, uma vez que ao se aumentar a fluxo, aumentam-se as forças mobilizantes, logo afeta-se negativamente também o F.S. da estrutura.

Tal situação da variação da posição da linha d'água, ou mesmo elevação da linha d'água acima do rejeito, pode ser explicada em uma situação real por diferentes fatores, desde variação da posição de lançamento dos rejeitos, variação da porcentagem de líquido em polpa a precipitações intensas. Assim, percebe-se que um projeto de monitoramento adequado de barragens deve prever o monitoramento piezométrico das pressões de água e consequentemente do comportamento do fluxo d'água no barramento.

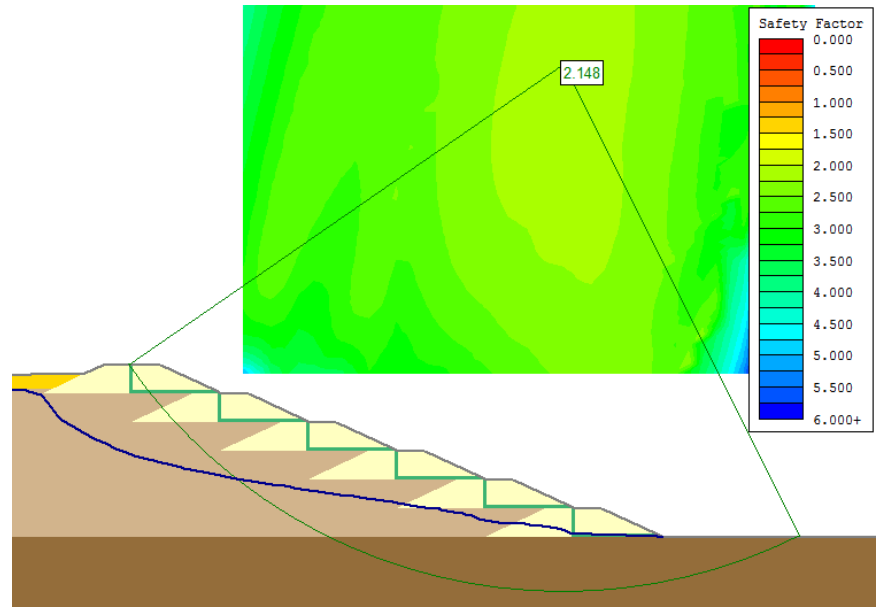

Figura 9 - Posição da linha piezométrica e queda do Fator de Segurança, com linha d'água a 75 metros do barramento, com F.S. de 2,148.

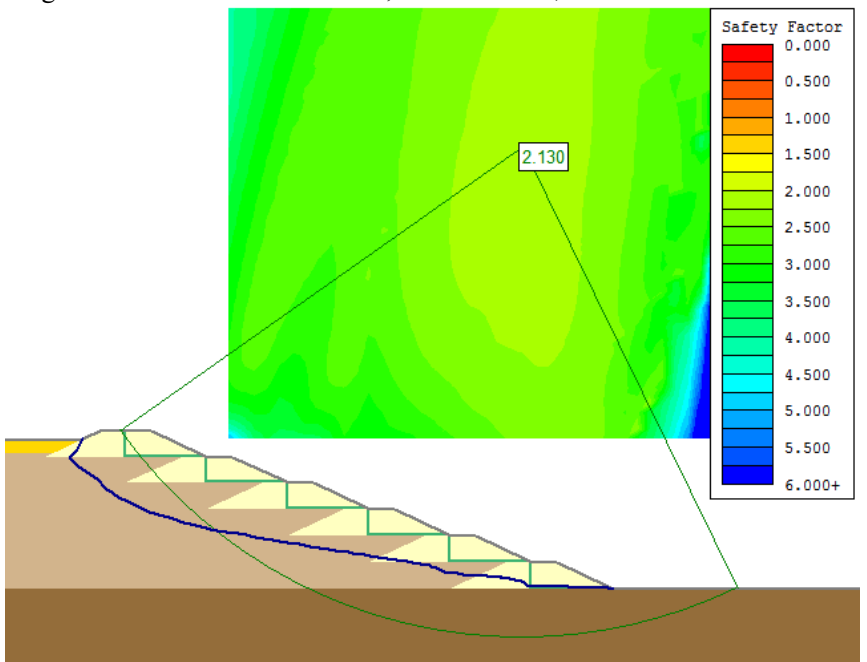

Figura 10 -'Posição da linha piezométrica e queda do Fator de Segurança, com linha coincidente com o barramento, com F.S. de 2.130.

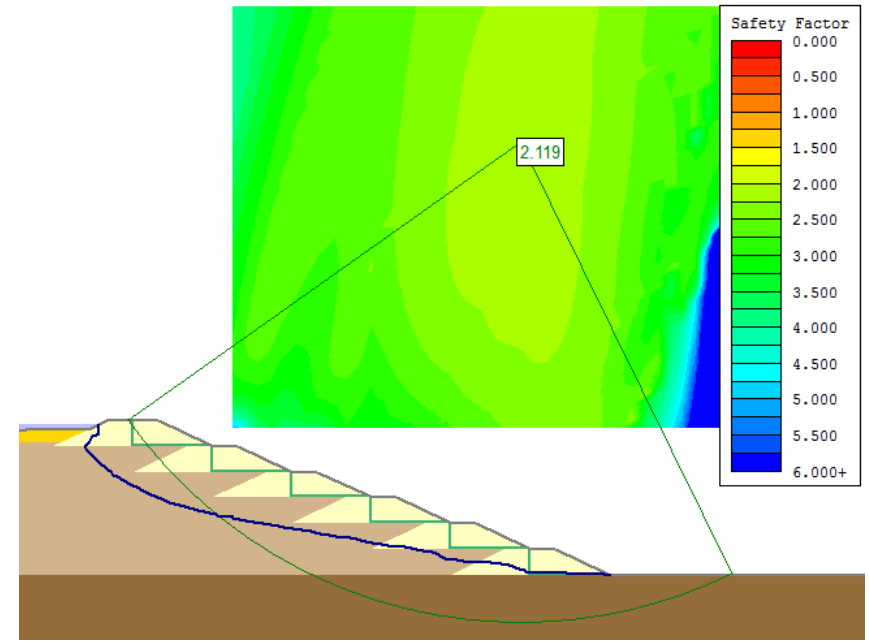

Figura 11 -'Posição da linha piezométrica e queda do Fator de Segurança, com linha 1,5 metros acima do rejeito, com F.S. de 2.119. 


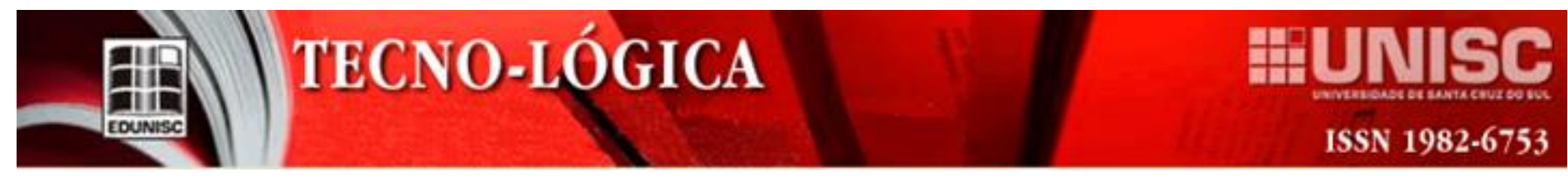

\subsubsection{Alterações na disposição de rejeito}

A ocorrência de camadas, alternadas ou não, de rejeito com propriedades e espessuras diversas, é algo factível. Dado a dinâmica da mineração (anisotropia natural dos corpos de minérios) e do beneficiamento, bem como diferentes taxas de deposição do rejeito são fatores que podem levar a cenários não previstos inicialmente em estudos iniciais de um barramento.

A variabilidade de propriedades dos rejeitos pode ser observada em trabalhos de caracterização in situ como os de De Araújo [11], Albuquerque Filho [21], Pereira [27] e Rafael e Romanel [18]. Embora, seja compreensível que a previsão do comportamento das propriedades do rejeito seja algo de grande complexidade. Para ilustrar a influência de variações nas propriedades do rejeito os modelos das Figuras 12, 13, 14 e 15; apresentam hipóteses de uma maior espessura de rejeito disposto (17 metros), logo com resistência inferior ao adensado, com linha d'água a 150 metros do barramento (Figura 12) e; com linha d'água a 1,5 metros acima do rejeito (Figura 13). Na Figura 14, é apresentada a situação de uma camada de rejeito de 7 metros (por simplificação com mesmas propriedades do rejeito disposto) dentre a camada de rejeito adensado e na Figura 15, tem-se a mesma situação mas com linha d'água a 1,5 metros acima do rejeito. Em ambos os caso os menores F.S.'s foram nas situações com a nível d'água elevado, sendo 1,949 para maior espessura de rejeito disposto e 2,016 no caso com uma camada intercalada.

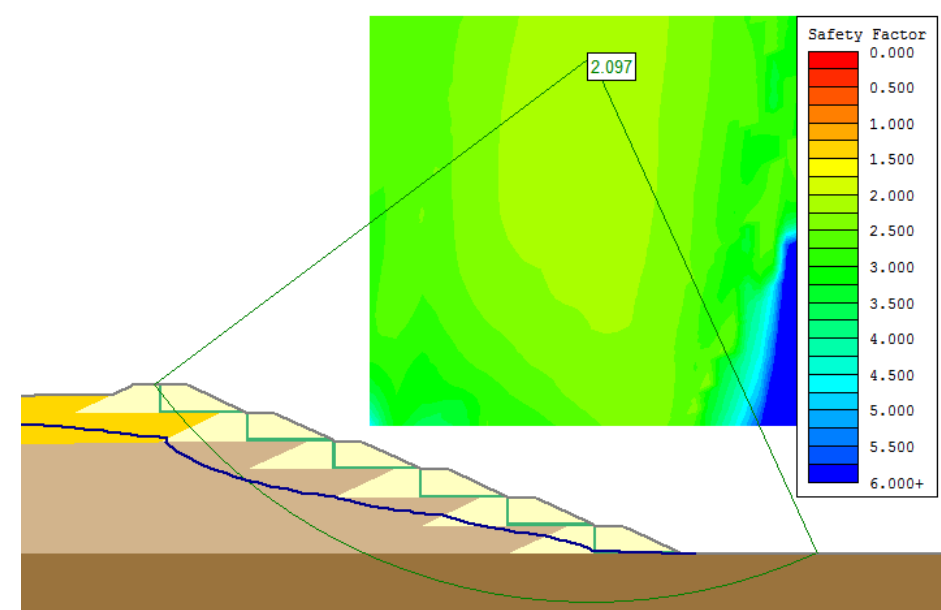

Figura 12 - Modelo com camada de rejeito disposto de maior espessura, com F.S. de 2,097 .

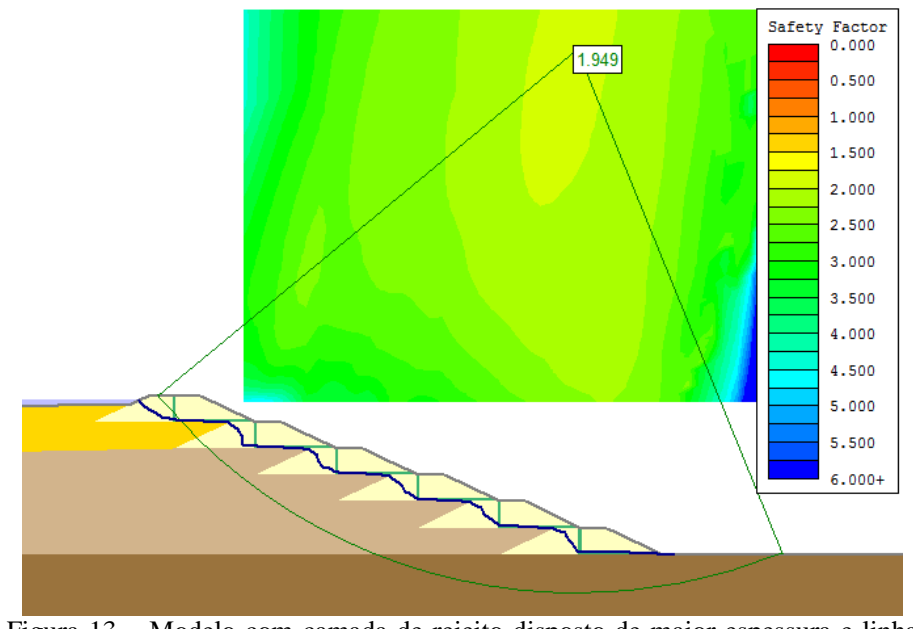

Figura 13 - Modelo com camada de rejeito disposto de maior espessura e linha d'água 1,5 metros acima do rejeito, com F.S. de 1,949.

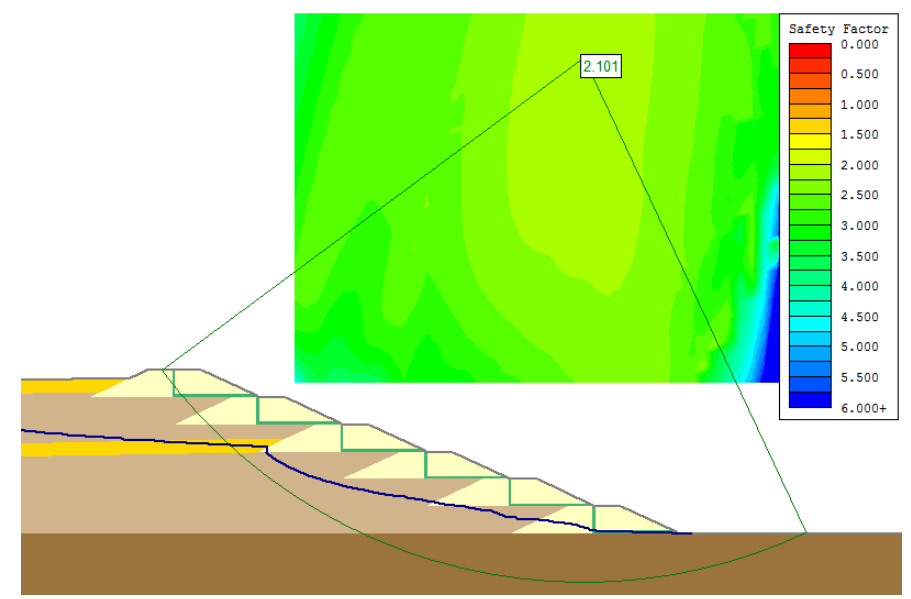

Figura 14 - Modelo com intercalação de camadas intercaladas de rejeito com diferentes propriedades, praia de rejeito a 150 metros, F.S. de 2,101

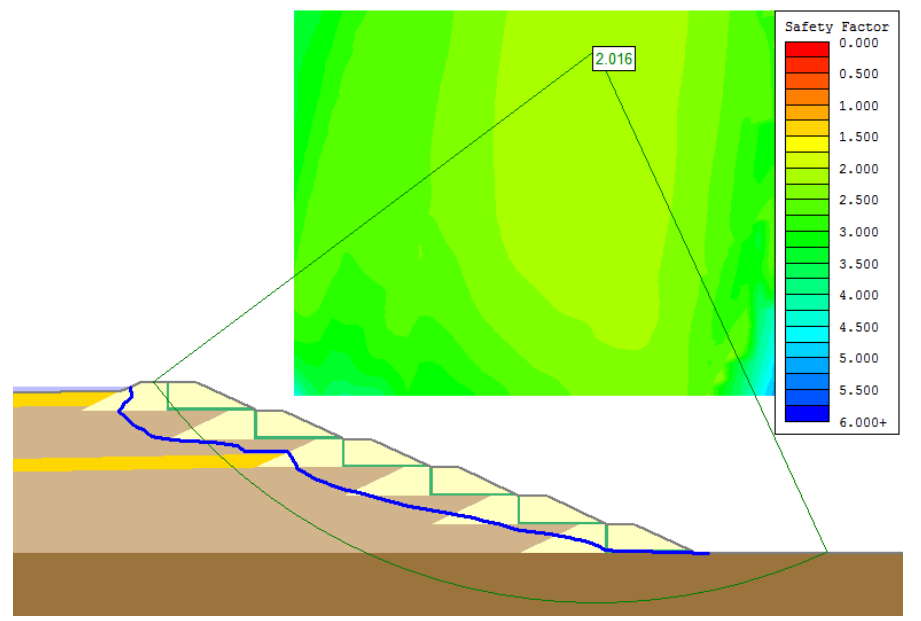

Figura 15 - Modelo com intercalação de camadas de rejeito com diferentes propriedades, nível d'água 1.5 metros acima do rejeito, F.S. de 2,016. 


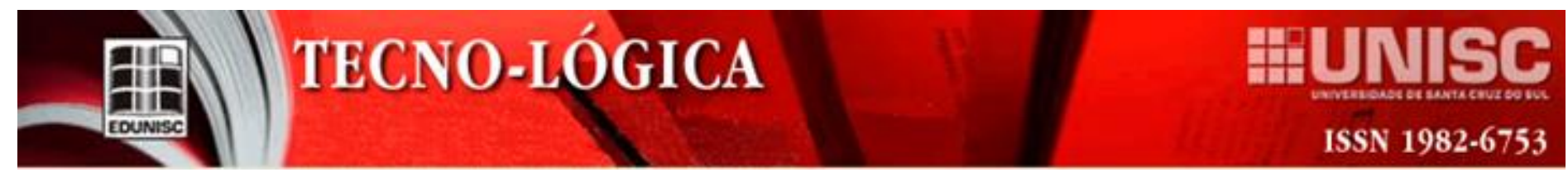

\subsubsection{Variações de Parâmetros Geométricos}

Ao fato de barragens de rejeito serem estruturas executadas em etapas que acompanham a vida útil de uma operação mineira, deve-se o grande tempo de execução da mesma, o que por vezes pode-se culminar em alteração de execução frente aos projetos iniciais, embora é prudente considerar que para tanto os projetos e análises devem ser refeitos e adaptados as novas realidades que podem vir a se apresentar. Exemplos típicos são alterações nas reservas minerais (as quais podem ser aumentadas no decorrer da operação, em função de novos dados de pesquisa), que levam a necessidade de alterações nos projetos de barramento, seja por novos alteamentos não previstos, seja por novas geometrias dos mesmos.

Podemos citar, inicialmente o simples projeto de alteamento, que deve levar em consideração a configuração final planejada do barramento, uma vez que está a priori seria a configuração mais desfavorável. Nas Figuras 16 e 17, que esboça o processo de suscetíveis alteamentos, vemos, entretanto, o acréscimo do F.S. em função dos acréscimos de alteamento, onde verificam para dois, quatro e seis alteamentos (caso base); fatores de segurança respectivamente de 2,154; 2,170 e 2,187.

Como exemplo da alteração da geometria de um barramento e seus possíveis danos podemos citar o evento de ruptura das barragens em Mariana/MG, o qual por sua vez culminou em grandes impactos sócio ambientais [3 e 4]. Quanto as causas da falha uma das principais causas apontadas em laudo [8], seria a disposição acelerada de rejeito que levou a necessidade de execução de alteamento em ritmo acelerado e com mudança de posicionamento do alteamento.

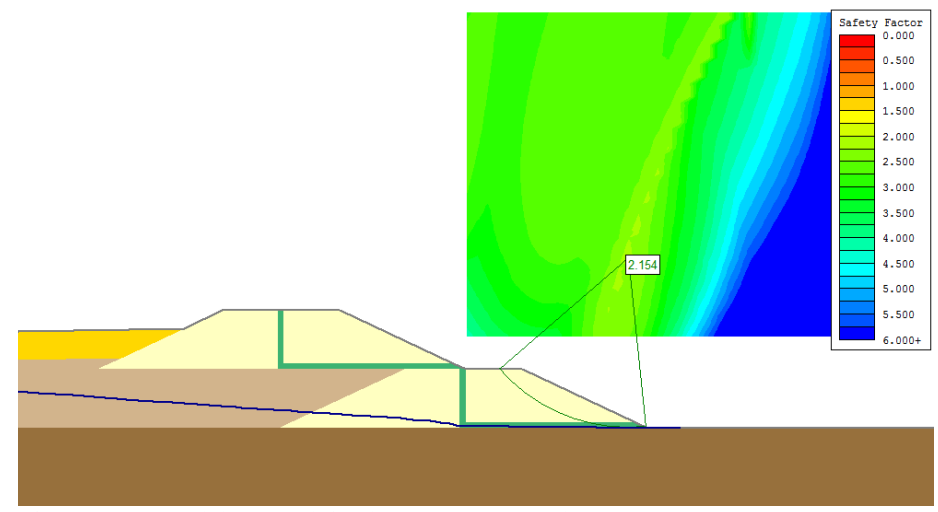

Figura 16 - Modelo com dois alteamentos, F.S. de 2,154.

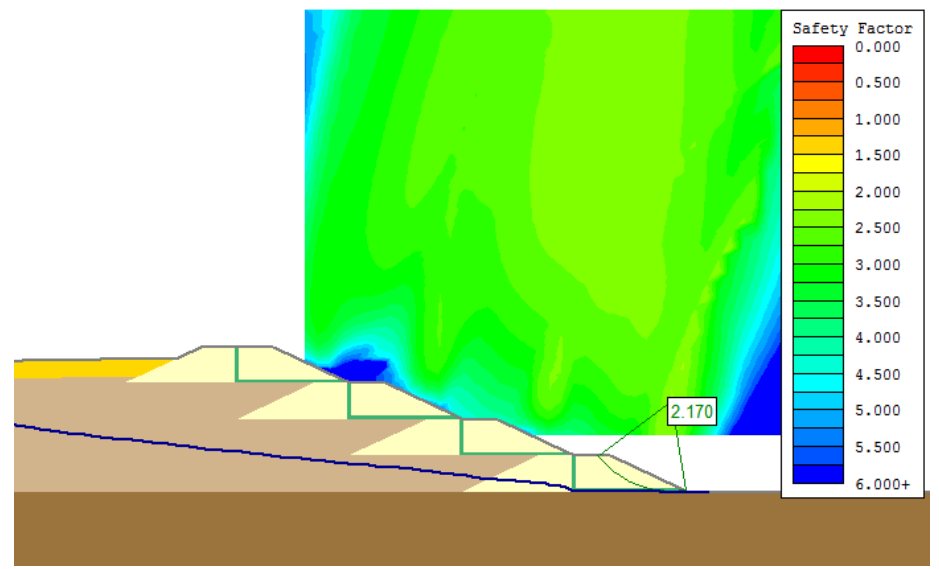

Figura 17 - Modelo com quatro alteamentos, F.S. de 2.170

As Figuras 18 e 19, apresentam situação hipotética, onde ocorre um deslocamento do barramento. Tal situação não incomum ao setor mineral, podendo ser decorrente de uma mudança repentina de planejamento, por exemplo, em função de alteração no ritmo de produção. Na Figura 19, é representada a hipótese combinada de deslocamento do barramento e elevação do nível d'água 1,5 metros acima do rejeito. Tem-se uma queda do F.S. de 2,279 para 2,178, do cenário com linha de praia a 150 metros para o cenário com nível d'água 1,5 metros acima do rejeito e coincidente com o barramento.

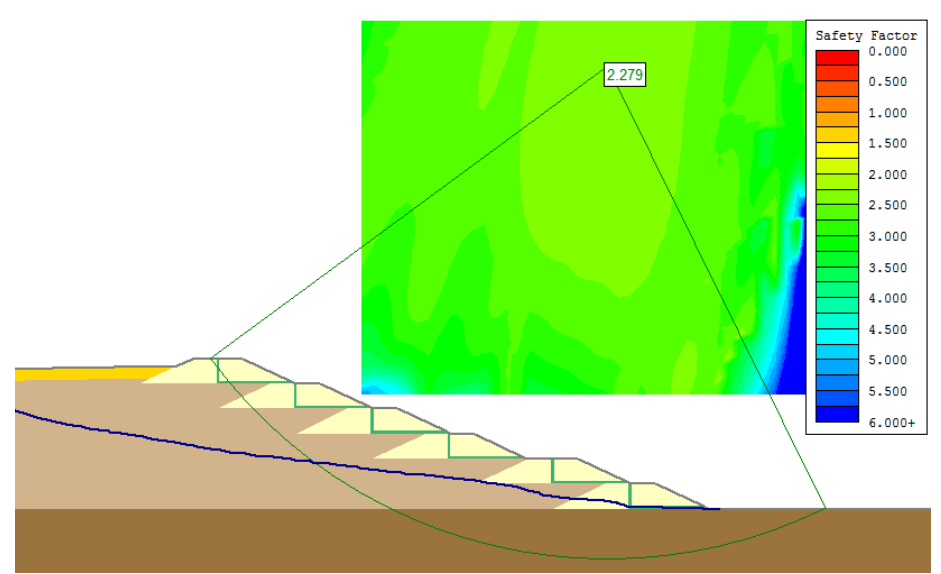

Figura 18 - Modelo com deslocamento do terceiro barramento, F.S. de 2,279. 


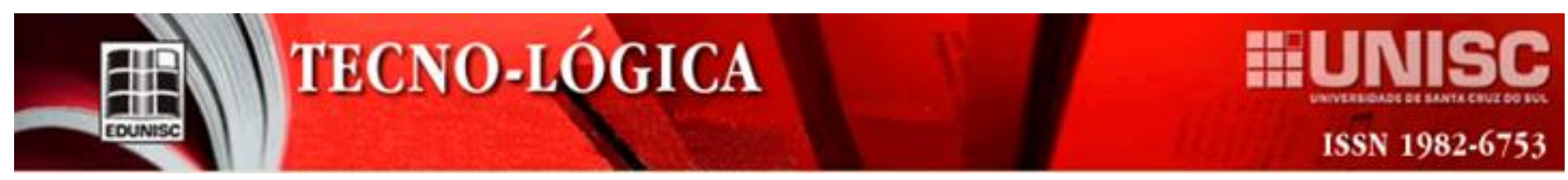

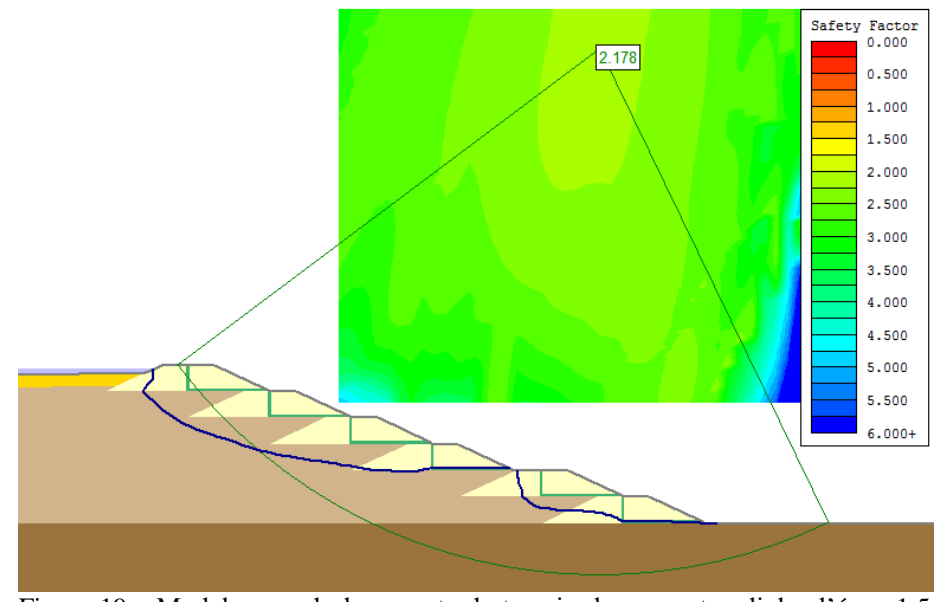

Figura 19 - Modelo com deslocamento do terceiro barramento e linha d'água 1.5 metros acima do rejeito, correspondendo a um F.S. de 2,178.

\subsubsection{Variações de Parâmetros Geotécnicos}

Como apresentado anteriormente variações de parâmetros geotécnicos podem ser consideradas com certa naturalidade para o caso de barragens de rejeito, uma vez que seria irreal considerarse que no decorrer de toda a operação de uma barragem os materiais manter-se-iam com propriedades constantes. A isso pode-se atribuir desde variações no próprio minério (modelo geológico) a variações nos processos de beneficiamento desde os de cominuição aos processos de concentração.

Assim como em qualquer obra de engenharia, variações de parâmetros de resistência de materiais construtivos, quando apresentam-se menores do que os considerados do projeto, tem-se o risco de colapso da estrutura. Em tais casos depara-se com forças resistivas menores que planejadas, e/ou maiores forças mobilizantes (oriundas, por exemplo, de maiores densidades de materiais).

Para ilustrar a variabilidade imposta ao modelo devido a possíveis variações de propriedades geotécnicas (c', $\gamma$ e $\varphi$ ) foi realizada uma Análise de Risco para estes parâmetros, considerando o Modelo Base, onde no software foi executada, juntamente, análise sensibilidade, a qual permite identificar os parâmetros críticos ao modelo, dado a influência de suas variações no F.S. Na Tabela 3, encontram-se os parâmetros variados, e os limites de variação, por simplificação optou-se por distribuição continua dos valores, dado o caráter ilustrativo da análise. $\underline{\text { Tabela } 3 \text { - Parâmetros geotécnicos e limites de variação considerados para análises }}$

\begin{tabular}{|c|c|c|c|c|c|}
\hline material & parâmetro & distribuição & provável & $\begin{array}{l}\text { limite } \\
\text { inferior }\end{array}$ & $\begin{array}{l}\text { limite } \\
\text { superior }\end{array}$ \\
\hline aterro & $c^{\prime}\left(\mathrm{kN} / \mathrm{m}^{\circ}\right)$ & Uniforme & 10 & 0 & 28.8 \\
\hline aterro & $\varphi^{\prime}\left(^{\circ}\right)$ & Uniforme & 36 & 15 & 42 \\
\hline $\begin{array}{l}\text { aterro } \\
\text { rejeito }\end{array}$ & $\gamma\left(\mathrm{kN} / \mathrm{m}^{3}\right)$ & Uniforme & 24 & 16 & 33 \\
\hline $\begin{array}{l}\text { adensado } \\
\text { rejeito }\end{array}$ & $\mathrm{c}^{\prime}\left(\mathrm{kN} / \mathrm{m}^{\circ}\right)$ & Uniforme & 0 & 0 & 6 \\
\hline $\begin{array}{l}\text { adensado } \\
\text { rejeito }\end{array}$ & $\varphi^{\prime}\left(^{\circ}\right)$ & Uniforme & 36 & 24 & 42 \\
\hline $\begin{array}{l}\text { adensado } \\
\text { rejeito }\end{array}$ & $\gamma\left(\mathrm{kN} / \mathrm{m}^{3}\right)$ & Uniforme & 22 & 18 & 24 \\
\hline $\begin{array}{l}\text { disposto } \\
\text { rejeito }\end{array}$ & $\mathrm{c}^{\prime}\left(\mathrm{kN} / \mathrm{m}^{\circ}\right)$ & Uniforme & 0 & 0 & 20 \\
\hline $\begin{array}{l}\text { disposto } \\
\text { rejeito }\end{array}$ & $\varphi^{\prime}\left(^{\circ}\right)$ & Uniforme & 20 & 18 & 36 \\
\hline disposto & $\gamma\left(\mathrm{kN} / \mathrm{m}^{3}\right)$ & Uniforme & 20 & 0 & 24 \\
\hline fundação & $\mathrm{c}^{\prime}\left(\mathrm{kN} / \mathrm{m}^{\circ}\right)$ & Uniforme & 20 & 0 & 22 \\
\hline fundação & $\varphi^{\prime}\left(^{\circ}\right)$ & Uniforme & 35 & 0 & 42 \\
\hline fundação & $\gamma\left(\mathrm{kN} / \mathrm{m}^{3}\right)$ & Uniforme & 20 & 15 & 24 \\
\hline
\end{tabular}

Foi definido para a análise a opção de busca global probabilística, a qual executa simulações de cenários não só na superfície considerada como crítica no caso determinístico (caso base, sem incorporação da variabilidade), mas em todo o quadrante de busca, assim, realizando simulações para todas as superfícies de busca. Devido a limitações de cálculo computacional foram limitadas a 500 simulações pelo método de Monte Carlo.

A Figura 20, abaixo apresenta a análise de sensibilidade, onde se observa e influência da variação das propriedades geotécnicas dos materiais dos modelos. Nesta análise vê-se que parâmetros, como ângulo de atrito do rejeito, tem grande influência no F.S do modelo. Em comparação parâmetros como coesão, para todos os materiais, e parâmetros do aterro, não apresentam influencia considerável no Modelo Base. Comparando-se os F.S.'s em função dos parâmetro geotécnicos individualmente (gráfico scatter plot), tem-se que a maior correlação (58.8\%) se verifica para o ângulo de atrito do rejeito disposto (Figura 21), sendo que de modo geral apenas para os ângulos de atrito (dos demais materiais) se verificou tendências, não sendo verificada correlações nos demais parâmetros (considerando o modelo estudado). 


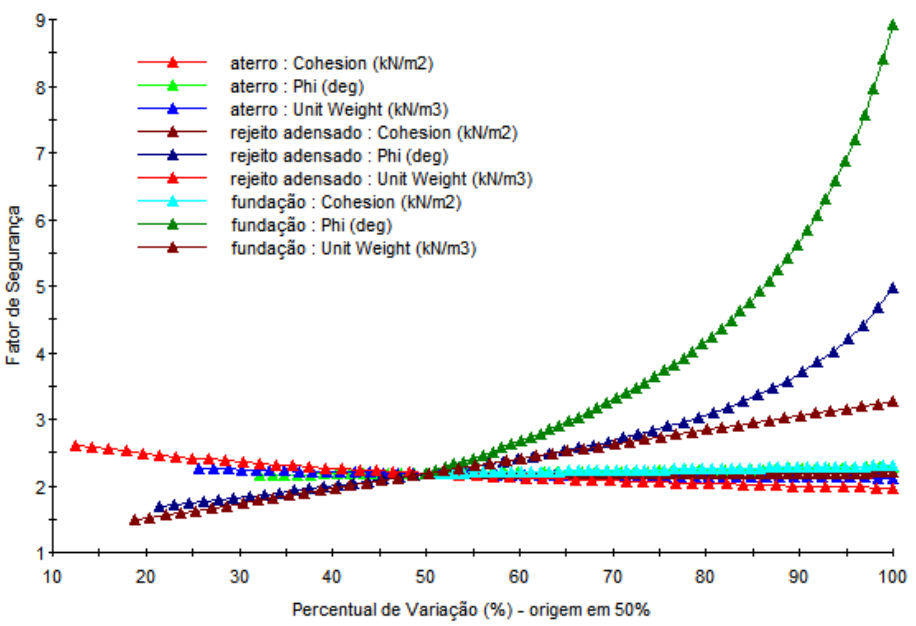

Figura 20 - Análise de Sensibilidade da variação das propriedades geotécnicas no Modelo Base

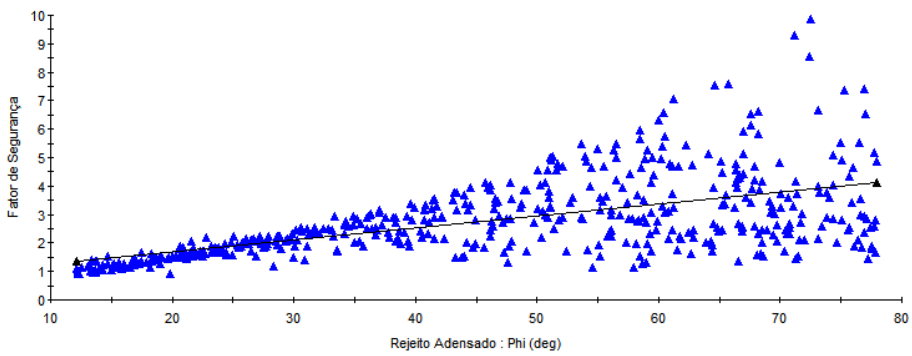

Figura 21 - Scatter plot do F.S. em função ao ângulo de atrito do rejeito adensado.

A Figura 22, abaixo, apresenta o histograma dos resultados das simulações rodadas (Análise de Risco), destaca-se quanto a este, que o mesmo apresenta caráter ilustrativo quanto a variabilidade que o F.S. de um modelo pode assumir frente a variabilidade dos dados de entrada, no caso, as propriedades geotécnicas de projeto. Verifica-se que existe divergência entre o F.S. determinístico e os F.S.'s mais prováveis, para o caso em questão o F.S. mais provável fica acima do F.S. determinístico uma vez que a distribuição encontrada teve um F.S. médio de 2,776 , embora isto se deva aos modelos de distribuição adotados e aos parâmetros considerados como variáveis, estes arbitrados de forma ilustrativa. Possivelmente ao se considerar outras distribuições de valores seria possível encontrar um F.S. médio com valor inferior ao F.S. determinístico.

No exemplo da Figura 22, 41,2\% (em vermelho no histograma) das simulações apresentaram F.S. abaixo do F.S. determinístico, bem como os resultados apresentaram uma distribuição próxima do modelo de distribuição lognormal, com média de 2,776; desvio padrão de 1,395; e mínimo e máximo de 0,9016 e 9,948; respectivamente. Cabe salientar que em comparação com o F.S. recomendado para barragens de rejeito $(1,5)$, temos que $13,8 \%$ das simulações ficaram abaixo deste valor.

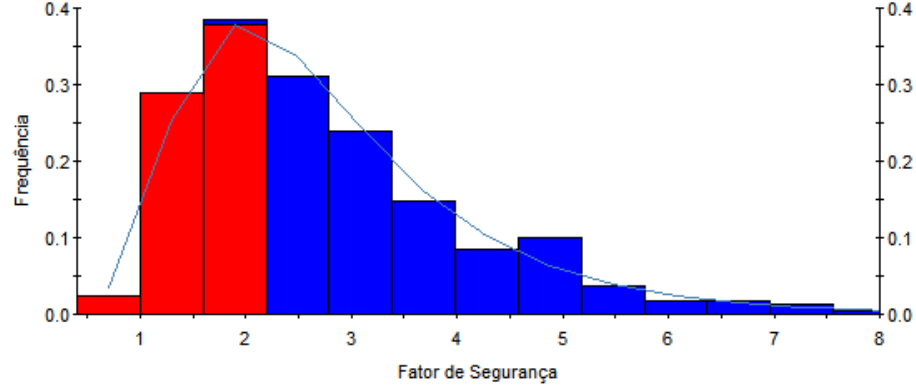

Figura 22 - Histograma da simulação de Fatores de Segurança

\section{Abordagens para minimização e gerência sobre os riscos na disposição de rejeitos da mineração}

Como debatido, diversos são os riscos associados a disposição de rejeitos em barramentos, entretanto, a de se considerar que por tratar-se de uma atividade econômica de grande representatividade e sendo responsável por insumos fundamentais ao desenvolvimento da sociedade, é plausível considerar que restrições ao desenvolvimento da atividade de mineração são em termos globais inviáveis, bem como tornam-se em diversas situações locais, antieconômicas. Deste modo, assim como a avaliação adequada dos riscos e sua minimização em termos estruturais, por meio de medidas estruturais e controle construtivo de matérias; outras ações como monitoramento, instrumentação e medidas de otimizações dos processos unitários, são passiveis de aplicação como medidas atenuantes dos riscos associados a barragens de rejeito.

\subsection{Monitoramento e Instrumentação}

Basicamente como demandam as boas práticas de gerenciamento de qualquer obra geotécnica, a correta instrumentação da obra em suas várias etapas executivas e de operação; é fator fundamental para a boa confiabilidade quanto a mesma, sua estabilidade ou predição de falha (de modo a minimizar danos e perdas).

Considera-se que a eficiente medição dos parâmetros desejados, segundo Bressani [29] está relacionada com as etapas de: (i) planejamento da instrumentação, (ii) definição da posição e tipo de instrumentação, (iii) definição do pessoal responsável e (iv) análise crítica dos dados, sendo qualquer uma destas etapas possíveis fontes de erros e falhas. Ainda segundo Bressani [29] são instrumentos de medição mais comuns: pluviômetros, piezômetros, inclinômetros, extensômetros células de carga, tensiômetros, entre outros.

Falhando-se nos procedimentos de instrumentação, etapas posteriores, assim, serão abastecidas com dados 
inverídicos, ou com variabilidade considerável, afetando-as. Sendo etapas posteriores, calibrações de modelos numéricos (entre outros), verificação do desempenho e apontamento de medidas de mitigação de falhas.

Hu e Liu [30], apontam que a utilização dos dados de monitoramento de forma automatizada, inteligente e conectada; constituem forma adequada de estruturação de um sistema de monitoramento de segurança de barragens de rejeitos.

\subsection{Otimizações dos processos unitários}

De maneira geral, a otimização nos processos unitários (aumento da recuperação do minério) permite reduzir os volumes de rejeitos dispostos e consequentemente reduzir riscos associados. Entretanto para a disposição de rejeitos o teor de sólidos em polpa (fase sólida + fase líquida) é parâmetro de suma importância, que em caso de otimização (aumento do teor) beneficia estruturalmente a disposição, por se reduzir os volumes de líquido no barramento.

Por sua vez, o aumento da porcentagem de sólido em polpa, acarreta na necessidade de tratamentos adicionais para o desague de todo o rejeito a ser disposto. Tais processos de separação sólido-liquido são normalmente feitos por operações como ciclonagem, filtragem e espessamento. Embora tais processos sejam usuais para o caso de caracterização como em disposição em pilha, estes ganham uma maior intensidade uma vez que é necessário um menor teor de água.

De forma análoga, onde o intuito é diminuir consideravelmente a quantidade de fluido na polpa de rejeito, Martins e Vidal [31] e Caressato Junior et al. [32], apresentam o uso de tubos geotêxtis como uma interessante alternativa para desague e mesmo disposição final. Entretanto, considerando-se que tal técnica devido a custos apresenta maior compatibilização com minerações de menor escala (menores quantidades de rejeito), maiores potenciais de contaminação (logo que apresentam maiores custos de disposição e onde o custo de terreno (com desapropriação, aquisição, arrendamento, entre outros) se apresenta alto;

\section{Conclusões}

Este trabalho se propôs a analisar de forma analítica como variações em parâmetros de entrada em um modelo sintético de uma barragem de rejeito afetam a confiabilidade da estrutura, analisando-se a variação dos Fatores de Segurança (F.S.) e também nos fluxos d'água. Assim, procurou-se representar na forma de modelos computacionais situações que se apresentam como riscos a estrutura de um barramento. Após levantamento bibliográfico e estudo dos modelos desenvolvidos, podemos tecer as seguintes conclusões:
- Ao contrário do esperado, vê-se, conforme modelos desenvolvidos, que o acréscimo de alteamentos não afetou negativamente o Fator de Segurança da estrutura, embora observase que com tais acréscimos a superfície de ruptura tende a migrar do barramento (caso das etapas com dois e quatro alteamentos) para o rejeito (etapa final com seis alteamentos), passando as propriedades deste governar as forças resistivas. Tal situação, de acréscimo no F.S. no caso estudado, entendesse ser devido a influência do fluxo d'água, das poropressões geradas (negativas e positivas) e pelas propriedades mecânicas dos materiais considerados.

- Verificou-se que no método de alteamento a montante o afastamento de linha d'água da praia de rejeito, tem grande impacto na estabilidade da estrutura, uma vez que o devido afastamento (como no Modelo Base estudado, com 150 metros de afastamento) possibilita um afastamento da linha freática subterrânea do barramento e também da superfície de ruptura, assim diminuindo forças mobilizantes. Verifica-se que em tal cenário os drenos das porções inferiores são requeridos em detrimento de drenos locados nas porções superiores, embora como também salientado não deva ser descartada a hipótese de avanço da linha freática em proximidade ao barramento, cenário este dentre os estudados, que apresentaram maior impacto no F.S. do barramento.

- Na hipótese de eventual existência de uma camada de "argila mole" de baixa capacidade de suporte para fundação, verificou-se que tal cenário também afeta drasticamente o F.S., uma vez que superfícies de ruptura passam a ser orientadas por tal camada, embora assim como descrito em bibliografia voltada a barragens em geral [26, 33], o tratamento da fundação, como no caso apresentado, com a substituição da camada existente é uma solução satisfatória. Nesta situação verificou-se acréscimo significativo no F.S.. Deste modo, salienta-se quanto a necessidade de uma correta caraterização dos materiais de fundação e eventual tratamento da mesma.

- Referente a influência das propriedades hidráulicas dos materiais e do sistema de drenagem, verifica-se com base nos modelos, que o sistema de drenagem possui influência sobre a estabilidade da estrutura, principalmente em cenários em que o nível d'água se aproxima do barramento, sendo esta proximidade responsável por significativos decréscimos no F.S. em relação ao Modelo Base, bem como uma maior exigência por parte dos filtros e sistema de drenagem.

- Referente a eventuais variações das propriedades geotécnicas dos materiais dos modelos, verifica-se que estas têm grande influência no F.S. e no posicionamento de eventual superfície de ruptura. Salienta-se que conforme revisão bibliográfica, tipicamente rejeitos de mineração, apresentam grande variabilidade de propriedades mesmo os rejeitos de um 
mesmo minério. Assim pode-se perceber como as propriedades geotécnicas se apresentam como critério crítico de projeto e devem ser constantemente avaliados ao decorrer da vida do barramento. No caso em questão, considerando a análise de sensibilidade realizada, verificou-se uma grande influência para o ângulo de atrito dos materiais em função de dado a proporção do barramento, ser este o parâmetro que predomina como força resistente. Já a densidade da fundação se mostrou relevante, no estudo em questão, devido a parcela resistiva no equilíbrio de forças se dar na fundação.

Por fim conclui-se que feitas as devidas considerações de projetos e se atentando para as situações elencadas o método construtivo de alteamento a Montante é altamente interessante, nas condições estudas. Como trabalhos futuros aponta-se a viabilidade de expansão das análises feitas para modelos numéricos e tridimensionais, bem como o estudo da influência de outros fatores como a deformabilidade dos materiais e da influência de sismos. Já a análise estatística e probabilística das propriedades dos materiais constituintes de modelos geotécnicos, se mostra como grande potencial de estudo, vide o potencial de variação entre F.S. determinístico.

\section{Considerações Finais}

Conforme o presente estudo, e com base na bibliografia disponível, vemos que embora aparentemente restrita a área de mineração, barragens de rejeitos tratam-se de estruturas que requerem para sua construção e gerência, um claro conhecimento multidisciplinar onde diversas áreas de conhecimento devem interagir desde as áreas de geociências, de engenharia e de planejamento. Assim como em demais obras de engenharia, o conhecimento prévio (de investigação e caracterização geotécnica de materiais) é fundamental para a eficiência do projeto, vide o grande número de variáveis que apresentam impacto sobre a estabilidade de um barramento.

De mesmo modo, a gerência sobre os dados de caracterização e monitoramento da estrutura são muito importantes para a redução de riscos. Por fim, com em métodos de redução da geração de rejeitos e métodos alternativos de disposição, vê-se uma grande gama de alternativas, que em utilização conjunta tendem a contribuir para a redução de riscos em caso de falhas. Destaca-se que considerando escalas produtivas, tais metodologias, nem sempre se mostram alternativas viáveis, ou como alternativa única, sendo também possível um blende entre disposição convencional e métodos de redução de rejeitos; por exemplo, utilizando-se conjuntamente processos de maior eficiência de deságue com a disposição por barramento tradicional. Como visto nos modelos desenvolvidos no presente trabalho e em outras obras $[13,14,33]$, tem-se que um dos principais fatores a se observar nos projetos e na execução de barramentos de rejeitos é o fator hidráulico, logo medidas com a redução da fase líquida (menor quantidade de água) e afastamento da linha freática do barramento, tende-se em favor da segurança da estrutura.

Outros caminhos para a disposição de rejeitos de mineração, que podem substituir a utilização convencional de disposição de barragens, ou reduzi-la, são os métodos alternativos de disposição de rejeitos, como em cavas exauridas, pilhas, sem barramentos, ou ainda o reprocessamento de rejeitos [34-37]. Entretanto para o primeiro caso tem-se a limitação da dependência da existência de uma cava exaurida, já para disposições em pilha e sem barramento tem-se a necessidade de processos de deságue com maior eficiência. Assim como para o reprocessamento que necessita de existência de um mercado consumidor e de tecnologias de reprocessamento compatíveis com os teores de minério contidos nos rejeitos gerados.

\section{Agradecimentos}

Os autores agradecem aos revisores, pelas sugestões e aos editores pela oportunidade de divulgação do presente trabalho.

\section{RISK CONSIDERATIONS IN TAILINGS DAMS}

ABSTRACT: This work aims to address risks associated with mining reject dams as to the influence of variation of project parameters against the stability of the structure and possible alternatives project aimed at minimizing risks. For so much was accomplished through modeling of hypothetical dams, these with design parameters based on actual data of characterization of materials available in bibliography, the verification of the behavior of structures in the face of variations of Geotechnical and design parameters, where the sensitivity of the constructive methods was verified in the face of such variations. It was found that the upstream method of uploading has a greater sensitivity to variations, especially to criteria related to drainage, although this method presents greater economic performance. Regarding the minimization of risks are the presented methodologies and assumptions of projects and monitoring that vision manages it on the risk associated with the structure.

Keywords: Geotechnical engineering. Tailing dams. Risk analysis.

\section{Referências}

[1] CURI, Adilson. Lavra de Minas. Oficina de Textos, 2017.

[2] CHAVES, Arthur Pinto. Teoria e prática do tratamento de minérios. Signus, 1996.

[3] AIRES, Uilson Ricardo Venâncio et al. Changes in land use and land cover as a result of the failure of a mining tailings dam in Mariana, MG, Brazil. Land Use Policy, v. 70, p. 63-70, 2018. 
[4] BURRITT, Roger L.; CHRIST, Katherine L. Water risk in mining: Analysis of the Samarco dam failure. Journal of Cleaner Production, v. 178, p. 196-205, 2018.

[5] AZAM, Shahid; LI, Qiren. Tailings dam failures: a review of the last one hundred years. Geotechnical News, v. 28, n. 4, p. 50-54, 2010.

[6] KOSSOFF, David et al. Mine tailings dams: characteristics, failure, environmental impacts, and remediation. Applied Geochemistry, v. 51, p. 229-245, 2014.

[7] DAVIES, M. P. et al. Design of tailings dams and impoundments. Keynote address, Tailings and Mine Waste Practices SME, AGM Phoenix, p. 1-18, 2002.

[8] XIN, Zheng; XIAOHU, Xu; KAILI, Xu. Study on the risk assessment of the tailings dam break. Procedia Engineering, v. 26, p. 2261-2269, 2011.

[9] FIORI, Alberto Pio. Fundamentos de mecânica dos solos e das rochas. Oficina de Textos, 2016

[10] MAFRA, J. M. Q. Barragem construída com rejeito ciclonado: uma possível solução para disposição de rejeitos no Brasil?. In: XVII Congresso Brasileiro de Mecânica de Solos e Engenharia Geotécnica, Belo Horizonte, MG. 2016.

[11] DE ARAÚJO, Cecília Bhering. Contribuição ao estudo do comportamento de barragens de rejeito de mineração de ferro. Tese de Doutorado. Universidade Federal do Rio de Janeiro. 2006.

[12] CARDOZO, Fernando Alves Cantini; PIMENTA, Matheus Montes; ZINGANO, André Cezar. Métodos Construtivos de Barragens de Rejeitos de Mineração-Uma Revisão. HOLOS, v. 8, p. 77-85, 2016.

[13] ROUT, Subrat; SAHOO, Tapaswini; DAS, Sarat. Design of tailing dam using red mud. Open Engineering, v. 3, n. 2, p. 316-328, 2013.

[14] CARDOZO, F. A. C.; PEÑA, F. P.; ZINGANO, A. C. Considerações e Comparações entre Métodos Construtivos de Barragens de Rejeito. In: IX Congresso Brasileiro de Mina a Céu Aberto \& Subterrânea. Anais. Belo Horizonte, MG. 2018.

[15] SANTOS, D .A. M dos; CURI, A.; SILVA, J. M. da. Técnicas para a disposição de rejeitos de minério de ferro. In: VI Congresso Brasileiro de Mina a Céu Aberto \& Subterrânea. Anais. Belo Horizonte, MG. 2010.

[16] LEITE, E.; GUNDIM, R. Identificação dos Riscos em uma Barragem de Mineração. In: IX Congresso Brasileiro de Mina a Céu Aberto \& Subterrânea. Anais. Belo Horizonte, MG. 2018.

[17] GALO, D.; LEITE, E. O Dnpm-Ba e A Gestão da Segurança das Barragens de Rejeitos. In: IX Congresso Brasileiro de Mina a Céu Aberto \& Subterrânea. Anais. Belo Horizonte, MG. 2018.

[18] RAFAEL, H. M. A. M.; ROMANEL, Celso. Potencial de Liquefação Estática no Alteamento de uma Barragem de Rejeito. In: XVI Congresso Brasileiro de Mecânica de Solos e Engenharia Geotécnica. Anais. Goiânia, GO, Brasil. 2014.

[19] PALMEIRA, Ennio M.; BEIRIGO, Elder A.; GARDONI, Maria G. Tailingsnonwoven geotextile filter compatibility in mining applications. Geotextiles and Geomembranes, v. 28 , n. 2, p. 136-148, 2010.

[20] DA SILVA, Leandro A.; MAZZINGHY, Douglas B.; VIANA, Paulo R. e CANDIA, Renan C. Avaliação do Adensamento de Rejeitos Finos de Minério de Ferro e sua Associação com a Mineralogia. In: IX Congresso Brasileiro de Mina a Céu Aberto \& Subterrânea. Anais. Belo Horizonte, MG. 2018.
[21] ALBUQUERQUE FILHO, Luiz Heleno. Avaliação do comportamento geotécnico de barragens de rejeitos de minério de ferro através de ensaios de Piezocone. Dissertação de Mestrado. Universidade Federal de Ouro Preto 2004.

[22] NAEINI, Mahdi; AKHTARPOUR, Ali. Numerical analysis of seismic stability of a high centerline tailings dam. Soil Dynamics and Earthquake Engineering, v. 107, p. 179-194, 2018.

[23] SHAMSAI, Abolfazl et al. Geotechnical characteristics of copper mine tailings: a case study. Geotechnical and Geological Engineering, v. 25, n. 5, p. 591602, 2007.

[24] SILVA, M. V. de S. Desafios na simulação de cenários de deposição de rejeitos dispostos hidraulicamente. In: IX Congresso Brasileiro de Mina a Céu Aberto \& Subterrânea. Anais. Belo Horizonte, MG. 2018.

[25] DIAS, Francisco Miguel dos Santos Carreto. Filtros em barragens de aterro: caracterização da sua permeabilidade. Dissertação de Mestrado. Universidade Nova de Lisboa. 2015.

[26] MACIEL FILHO. Carlos L.; NUMMER, Andrea. V. Introdução à Geologia de Engenharia. Editora UFSM. 2014.

[27] PEREIRA, Eleonardo Lucas. Estudo do potencial de liquefação de rejeitos de minério de ferro sob carregamento estático. Dissertação de Mestrado. Universidade Federal de Ouro Preto. 2005

[28] MORGENSTERN, N. R. et al. Fundão Tailings Dam Review Panel Report on the Immediate Causes of the Failure of the Fundão Dam. Cleary Gottlieb Steen \& Hamilton LLP, New York, 2016.

[29] BRESSANI, L. A. Instrumentação em obras geotécnicas-taludes e escavações. In: Conferência Brasileira de Estabilidade de Encostas. Anais. São Paulo, SP. 2009.

[30] HU, Jun; LIU, Xingzong. Design and implementation of tailings dam security monitoring system. Procedia Engineering, v. 26, p. 1914-1921, 2011.

[31] MARTINS, P.; VIDAL, DTubos Geotêxteis para Acondicionamento e Desaguamento de Rejeitos de Mineração. In: XII Encontro de Iniciação Científica e Pós-Graduação do ITA. Anais. São José dos Campos, SP. 2006.

[32] CARESSATO JUNIOR, W.; PANTA, C. A. C.; URBAN, R. C. Desidratação dos Rejeitos Provenientes da Mineração através de Tubos Geotêxteis. In: XVII Congresso Brasileiro de Mecânica de Solos e Engenharia Geotécnica. Anais. Belo Horizonte, MG 2016

[33] DA CRUZ, Paulo Teixeira. 100 barragens brasileiras: casos históricos, materiais de construção, projeto. Oficina de Textos, 1996.

[34] FRANKS, Daniel M. et al. Sustainable development principles for the disposal of mining and mineral processing wastes. Resources policy, v. 36, n. 2, p. 114-122, 2011

[35] FERREIRA, M. T. S. Aterros Experimentais dos Métodos Alternativos de Disposição de Rejeitos. Apresentação. In: IX Congresso Brasileiro de Mina a Céu Aberto \& Subterrânea. Apresentação. Belo Horizonte, MG. 2018.

[36] EDRAKI, Mansour et al. Designing mine tailings for better environmental, social and economic outcomes: a review of alternative approaches. Journal of Cleaner Production, v. 84, p. 411-420, 2014

[37] GUERRA, B. B., PIMENTEL, M. F. S., GOMES, A. C. Caracterização Tecnológica no Reprocessamento de Material Estocado em Barragem de Rejeito. In: IX Congresso Brasileiro de Mina a Céu Aberto \& Subterrânea. Anais. Belo Horizonte, MG. 2018. 